\title{
CyberSpace \\ Useful information on the world wide web
}

Web based information about patient safety and quality improvement-both popular and academic -is proliferating rapidly as the quality/safety movement gathers momentum in the United States, Australia, the UK, New Zealand, Canada, Scandinavia, Switzerland, and elsewhere around the world. One may ask-how useful is this online information? Who accesses it, for what ends, with what outcomes? How well does it translate across national, cultural, linguistic, professional, and disciplinary boundaries? And are patients safer because of it? We lack even tentative answers to such questions at present.

\section{Online resource updates}

Quality and Safety in Health Care will sort through the onslaught of online articles, reports, and opinions on patient safety and healthcare quality, and periodically summarize them on our website. In addition, the print edition of QSHC will provide summary guides to electronic resources on particular topics and themes. These may include cultural factors that promote or hinder the creation of safer health care; the potential of patient advocacy efforts to improve patient-provider communication and avoid unnecessary litigation; and lessons from non-medical research disciplines, such as organisational behavior, human factors engineering, and risk perception and communication. We will spotlight these issues using an interdisciplinary and international approach that draws on the perspectives of relevant stakeholders in different health systems: patients, their families and caregivers, nurses, pharmacists, social workers, physicians, risk managers, laboratory technicians, health services researchers, quality managers, advocates, policy makers, system and facility managers, and journalists.

\section{Sites for sore eyes}

To begin, we provide a list of selected websites featuring patient safety and healthcare quality information and documents. This list is meant to be suggestive only-a starting point for a rich journey of discovery and learning. None of these sites stands alone; each offers links to other sites and sources.

Agency for Healthcare Research and Quality (http:// www.ahrq.gov/qual/errorsix.htm) $-A H R Q$ currently coordinates all US federal research on patient safety; in October 2001 it announced $\$ 50$ million in new grants (http://www.ahrq.gov/ news/press/pr2001/patsafpr.htm). AHRQ (pronounced "arc") also chairs the Quality Interagency Coordination Task Force (or QuIC), whose February 2000 report "Doing what counts for patient safety: federal actions to reduce medical errors and their impact" (http://www.quic.gov/report/index.htm) was a direct response to the Institute of Medicine's 1999 "errors" report. The QuIC convened public and private funders of safety research for a high profile National Summit on Medical Errors and Patient Safety Research in September 2000; invited and public testimony at the summit (http://www.quic.gov/summit/index.htm) has informed $A H R Q$ 's subsequent research agenda.

American Hospital Association (http://www.aha.org/ PatientSafety/Safe_home.asp) - The AHA, representing some 6000 US hospitals, has placed clinical quality and patient safety at the top of its public advocacy agenda.
American Society for Healthcare Risk Management (http:// www.ashrm.org/asp/home/PDF/whitepaper.pdf) - ASHRM, an affiliate of the American Hospital Association, published "Perspective on disclosure of unanticipated outcome information" in April 2001.

Anesthesia Patient Safety Foundation (http://www. apsf.org/) - The APSF was founded in 1984 "to ensure that no patient shall be harmed by anesthesia". Its quarterly newsletter is available online.

Australian Council for Safety and Quality in Health Care (http://www.safetyandquality.org/) • Australian health ministers appointed this panel in January 2000 "to lead national efforts to improve the safety and quality of health care". The Council issued its "First national report on patient safety" in August 2001 (http://www.safetyandquality.org/pdfs/firstreport.pdf).

Australian Patient Safety Foundation (http://www. apsf.net.au/index.html) - The foundation published a major report "latrogenic injury in Australia" in October 2001. It is not yet online, but a summary is available at http://www.apsf.net.au/ NewsletterMarO1.pdf.

Bristol Royal Infirmary Inquiry (http://www. bristol-inquiry.org.uk/final_report/index.htm) - This July 2001 report-an exhaustive investigation of bad outcomes in paediatric cardiac surgery-is a treasure trove of material on the professional and organizational roots of adverse medical events. Drill down into the archived testimony to find many excellent submissions from safety specialists.

British Medical Journal (http://www.bmi.com/) $~ B M$ published its comprehensive theme issue on medical error in March 2000 (http://bmi.com/cgi/content/full/320/7237/725).

Canadian Provincial Court of Manitoba (http://www. pediatriccardiacinquest.mb.ca/) - The November 2000 inquest report by Judge Murray Sinclair found "a failure of quality assurance and monitoring of the Health Sciences Centre Pediatric Cardiac Surgery Program" after 12 children died there in 1994. This land breaking report is a blueprint for reforming postgraduate oversight of physicians.

Critical Incidents Reporting System (http://www. anaesthesie.ch/cirs/) $>\operatorname{Dr}$ Sven Staender at the University of Basel facilitates the CIRS, "an anonymous and international forum on critical incidents in anaesthesiology".

Department of Health (http://www.doh.gov.uk) - In June 2000 the DoH released "An organization with a memory: report of an expert group on learning from adverse events in the NHS" (http://www.doh.gov.uk/orgmemreport/index.htm). This document "examines the key factors at work in organisational failure and learning" and recommends "creation of a new national system for reporting and analysing adverse health care events, to make sure that key lessons are identified and learned ...". A follow on report "Building a safer NHS for patients" (http:// www.doh.gov.uk/buildsafenhs/index.htm) outlines in greater detail a "new national system for learning from error and adverse events". The National Patient Safety Agency (http:// www.npsa.org.uk/html/npsa.htm) was launched in October 2001 to operate the new reporting system. 
General Accounting Office (http://www.gao.gov/archive/ 2000/he00021.pdf) - GAO released "Adverse drug events: the magnitude of health risk is uncertain because of limited incidence data" at a US Senate hearing in January 2000.

Institute for Healthcare Improvement (http://www.ihi.org/) - $\mathrm{HI}$ is a leading international healthcare quality improvement organisation. It serves as the National Programme Office for the "Pursuing perfection" initiative funded by the Robert Wood Johnson Foundation (http://www.ihi.org/pursuingperfection/ Inetwork/index.asp).

Institute for Safe Medication Practices (http://www. ismp.org/) - Founded in the 1970s, ISMP focuses on helping hospitals, practitioners, and patients prevent medication related injuries and deaths. It publishes the biweekly Medication Safety Alert. ISMP has affiliates in Canada and Spain.

Institute of Medicine (http://www.iom.edu/) - The massive media coverage given the IOM's November 1999 report "To err is human: building a safer health system" (http://www.nap.edu/ catalog/9728.html) helped to move patient safety well up the US (and global) policy agenda for much of 2000. The "errors" report, as it came to be known, also generated intense and sometimes acrimonious debate among safety researchers about whether estimating the annual mortality attributed to medical errors was either valid or useful. In March 2001 the IOM released a major report on quality in health care "Crossing the quality chasm: a new health system for the 21 st century" (http://www.nap.edu/ catalog/10027.html). The IOM's 1998 JAMA article "The urgent need to improve health care quality" (http://jama.ama-assn.org/ issues/v280n 1 1/abs/jst80006.html) is still worth reading.

Joint Commission on Accreditation of Healthcare Organizations (http://www.jcaho.org/ptsafety_frm.html) - The US based accrediting body's quality activities include its Sentinel Event Policy and revised Patient Safety Standards.

Leapfrog Group (http://www.leapfroggroup.org/) - Launched in 2000 by large corporate purchasers of health benefits, the Leapfrog Group aims to advance the "business case for safety" by encouraging safer and higher quality hospital care.

National Center for Patient Safety (http://www. patientsafety.gov/) - NCPS, part of the US Veterans Health Administration, is working to improve safety and quality across the system of veterans' health facilities by applying human factors principles and research on safe operation in high reliability organisations.

National Coalition on Health Care (http://www.nchc.org/ releases/medical_errors.pdf) - NCHC published "Reducing medical errors and improving patient safety: success stories from the front lines of medicine" in February 2000.

National Patient Safety Foundation (http://www.npsf.org/) - NPSF is an independent nonprofit organisation founded in 1997 by the American Medical Association, 3M Healthcare, CNA HealthPro, and Schering-Plough. NPSF and its partners have convened a series of influential "Annenberg" conferences; the next conference is in Indianapolis in April 2002 (http:// www.mederrors.org/). The NPSF also operates an active research program (http://www.npsf.org/html/research.html); publishes Focus, a quarterly newsletter (http://www.npsf.org/html/ publications.html); maintains an extensive online bibliography (http://www.npsf.org/html/bibliography.html); and hosts a popular email discussion list and current literature awareness alert with more than 1200 subscribers as of February 2002 (http://patientsafety-l@listserv.npsf.org/archives/index.html).

National Quality Forum (http://www.qualityforum.org/) - NQF is a non-profit, public-private membership organisation founded in 1999 to develop and implement a national strategy for health care quality measurement and reporting.

New Zealand Ministry of Health (http://www.moh.govt.nz/ moh.nsf/) - Recent reports include "Adverse events in New Zealand public hospitals: principal findings from a national survey" (December 2001) and "Toward clinical excellence: learning from experience" (September 2001).

Swiss Task Force on Patient Safety (http://www. swiss-q.org/apr-2001/docs/Final_ReportE.pdf) - The task force released "Towards a safe healthcare system: proposal for a national programme on patient safety improvement for Switzerland" in April 2001.

\section{Videos}

- "First, do no harm" (2000) is a dramatised case study of a healthcare system breakdown during the treatment of an obstetrics patient. (Available for purchase from Partnership for Patient Safety at http://www.p4ps.org/purchase_harm.html.)

- "Beyond blame" (1997) is a short documentary film on how medication errors affect all involved-practitioners and patients alike. (Available for purchase from Bridge Medical at http:// www.mederrors.com/.)

\section{Call for citations}

This is but a beginning. Kindly help us close the gaps by submitting citations for online materials-research reports, journal articles, proposed or enacted legislation, interactive websites, archived listserve messages - which you have found to be particularly useful for improving quality, creating safety, or preventing harm to patients in some relevant context or setting. We will review these materials for possible inclusion in future updates. We especially welcome citations (preferably in English translation, where available) for materials originating outside the "developed" world. Please send your citations to Adam L Scheffler at a-scheffler-1@alumni.uchicago.edu.

A L Scheffler Chicago, Illinois, USA a-scheffler-1@alumni.uchicago.edu 